\title{
Ferramentas de Geoprocessamento aplicadas no mapeamento do uso da terra no município de Jaguari/RS
}

\author{
GIS tools applied mapping land use in the municipality of Jaguari/Brazil
}

Bruno Zucuni Prina, Romario Trentin e Patrícia Ziani

Universidade Federal de Santa Maria, RS, Brasil

brunozprina@gmail.com; romario.trentin@gmail.com; pathyziani@hotmail.com

\begin{abstract}
Resumo
Este trabalho teve como objetivo realizar a identificação dos distintos usos da terra do município de Jaguaril RS por meio das ferramentas de geoprocessamento, com foco a verificação da localização espacial dos usos e de suas características. Além disso, foi estimado a quantidade de áreas plantadas (agricultura) no município. Neste sentido, foram utilizadas imagens de satélite da plataforma Landsat-8 imagens Shuttle Radar Topography Mission (SRTM), e, para analisar tais dados, o aplicativo Arcgis ${ }^{\circledast}$. Dessa forma, por meio da classificação digital supervisionada pelo método de máxima verossimilhança (Max Ver), pode-se estimar os usos da terra da área de estudo. Assim, após a classificação, verificou-se que os usos da terra mais presentes no município são: solo exposto $(35,3 \%)$, lavouras $(22,3 \%)$, vegetação $(22,1 \%)$ e os campos $(15,7 \%)$. Ainda, geraram-se análises particulares, dentro de cada território distrital, em 3 zonas altimétricas do município e, por fim, em 3 zonas clinográficas. Com isso,verificou-se, que tal metodologia de análise implica em uma importante ferramenta de auxílio à tomada de decisão, pois há uma grande contribuição no planejamento ambiental do município, bem como no conhecimento de dados para a gestão do território.
\end{abstract}

Palavras-chave: Landsat-8, Classificação Digital, Sensoriamento Remoto.

\begin{abstract}
This study aimed to carry out the identification of the different land uses the city of Jaguari/Brazil, through using Geoprocessing tools, with the focus of verify spatial location of uses and its specific characteristics. Besides, was estimated the amount of planted areas (agriculture) in the city. In focus, we were used satellite images the Landsat-8 platform, Shuttle Radar Topography Mission (SRTM) images, and to analyze the data, ArcGIS ${ }^{\circledR}$ the application. Thus, by supervised image classification by algorithms maximum likelihood (MaxVer) it can be estimated land uses the study area. Thus, after classification, it was found that land uses more presents in the city are: exposed soil $(35,3 \%)$, plantations $(22.3 \%)$, forests $(22.1 \%)$ and undergrowth (15.7\%). Still, specific analyzes were performed, within each territory of the districts, 3 altimetric areas of the city and at last, 3 slope areas. With that, it was verified, that this analysis methodology implies in a important tool for assistance to decision making, because there is a great help in environmental planning the city, as well as knowledge data for the management of the territory.
\end{abstract}

Keywords: Landsat-8, Digital Classification, Remote Sensing. 


\section{Introdução}

Muitos são os problemas que tangenciam o uso e a ocupação da terra, porém, há um maior destaque às ações do homem, o qual reconstrói o espaço geográfico, por meio da agricultura, da pecuária, assim como com a sua incidência visando a moradia, desmatando e remodelando a paisagem.

Weiss et al. (2013, p. 9210) enfatizam que "o uso inadequado do solo vem acarretando diversos problemas ambientais, tais como, o comprometimento de fontes e mananciais de água, degradação de habitats naturais, erosão, enchentes e assoreamento do solo". Nessa visão os autores contextualizam a problemática referente ao mau gerenciamento do espaço geográfico.

Ainda nessa questão, Amaral e Rios (2012, p. 2) destacam que o "levantamento do uso e ocupação do solo é imprescindível para analisar a forma pela qual determinado espaço está sendo ocupado". No que toca essa questão, denota-se que o conhecimento das feições do uso da terra de uma área, auxilia os planejadores e legisladores, uma vez que estes são os responsáveis por estabelecer diretrizes públicas quanto à utilização correta dos usos da terra.

Nesse foco, as ferramentas de geoprocessamento são extremamente importantes, principalmente no que tange a identificação, mapeamento e estimativa dos usos da terra, facilitando o entendimento de todo um território. Assim, explicita-se, a utilização do sensoriamento remoto na identificação das feições terrestres e dos Sistemas de Informações Geográficas (SIG), úteis no gerenciamento dos planos de informações e gerenciamento de informações.

Sob esta perspectiva, o objetivo geral do trabalho foi identificar os distintos usos da terra do município de Jaguari/RS por meio das ferramentas de geoprocessamento, enfatizando o sensoriamento remoto e o SIG.

Por conseguinte, os métodos aplicados nesse trabalho tangenciam a análise dos usos da terra no município de Jaguari, com foco na verificação da localização espacial dos usos e de suas características. Dessa forma, a caracterização geral foi adicionada a várias análises específicas, conforme ressaltado a seguir.

Realizou-se, assim, a correlação dos dados com os territórios dos distritos municipais, com alguns intervalos altimétricos e com a clinografia. Dessa forma, a proposta do trabalho foi de analisar a caracterização geral dos usos da terra no município. Além disso, efetuou-se a estimativa do número de áreas plantadas, englobando as diversas lavouras junto às áreas úmidas, que caracterizam a cultura orizícola.

"Quanto ao município de Jaguari, ressalta-se que o mesmo está localizado dentro da região centro-oeste do estado do Rio Grande do Sul próximo a coordenada geográfica de $29^{\circ} 29^{\prime} 51^{\prime \prime}$ de latitude Sul e de $54^{\circ} 41^{\prime} 32^{\prime \prime}$ de longitude Oeste (coordenada do centroide da área urbana), conforme disposto na Figura 1. Destaca-se que o mesmo está inserido na microrregião geográfica de Santa Maria.

Salienta-se que esse trabalho surge de uma complexa rede de análises realizadas em Jaguari que busca, basicamente, caracterizar as diferentes características presentes nesse território, verificando as homogeneidades e as heterogeneidades da sua paisagem, a fim de auxiliar no planejamento territorial desse município.

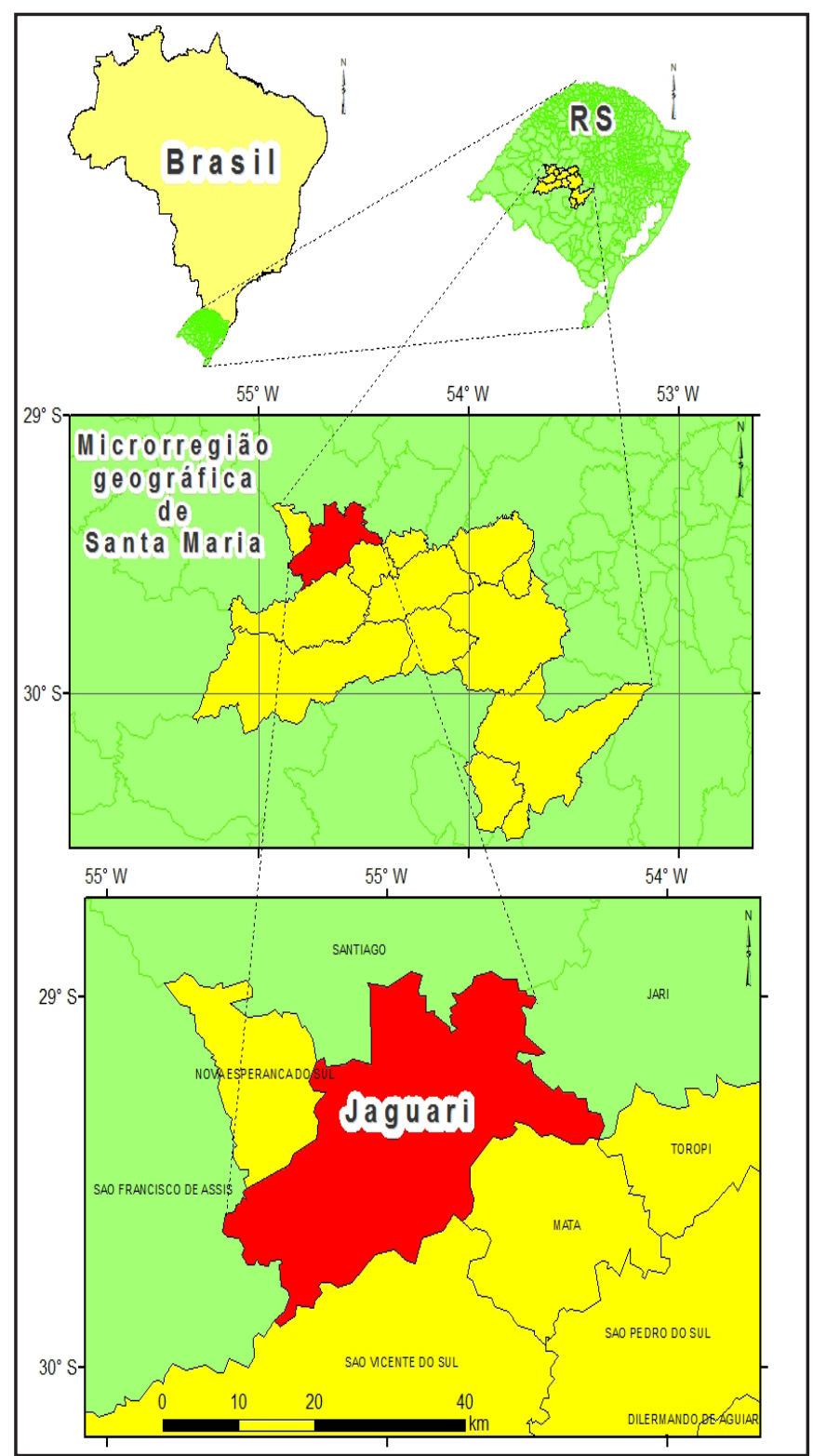

Figura 1- Mapa de localização da área de estudo Fonte: Elaborado pelos autores

\section{Materiais e Métodos}

Entre os materiais utilizados nesta pesquisa pode-se citar as imagens do sensor Landsat-8 e do Shuttle Radar Topography Mission (SRTM), ambas com resolução espacial de $30 \mathrm{~m}$, com exceção da banda pancromática do Landsat-8 (banda 8) a qual possui a resolução de $15 \mathrm{~m}$. As mesmas foram obtidas por meio do sítio do Serviço 
Geológico Americano (USGS - United States Geological Survey).

Em relação às imagens do sensor Landsat-8, deve-se ressaltar que foram utilizadas duas imagens de datas distintas, as quais representassem da melhor forma, o uso da terra "tanto do período de cultivo (out-mar), safra 2004/2005, como do período de entressafra (abrset), correspondente ao inverno, ano de 2005" (COLLISCHONN; COLLISCHONN, 2009, p. 4688). A distinção do presente trabalha para com o publicado por Collischonn e Collischonn (2009) é o ano, que ao invés de ser 2005 é 2014, mais especificamente datadas em 14 de julho de 2014 e de 14 de dezembro de 2014, sendo que a órbita/ ponto das imagens é de 223/80.

Referenciando a imagem do Landsat-8, pode-se destacar que foram utilizadas, para realização da classificação digital, as bandas do visível (bandas 2, 3 e 4), do infravermelho (bandas 5, 6 e 7), a pancromática (banda 8) e a banda costal (banda 1) de ambas datas. A referida etapa ocorreu por meio da utilização da ferramenta Composite Bands do Arcgis ${ }^{\circledast}$.

Referente a imagem SRTM, pode-se destacar que foi utilizado o "SRTM-1 Arc Second Global", o qual possui uma resolução espacial de 1 arco-segundo, o equivalente a um pixel de 30x30 m. A imagem do SRTM foi utilizada para criar o mapa de altimetria e de declividade da área de estudo.

Entre os aplicativos utilizados, pode-se destacar o ARCGIS $^{\circledast}$ e a planilha eletrônica do Excel ${ }^{\oplus}$. O ARCGIS foi utilizado como principal ferramenta para analisar os dados na estrutura de um Sistema de Informações Espaciais (SIG), a fim de gerar as análises espaciais destacadas nesse trabalho (sistematização dos mapas de altimetria e de declividade), além da aplicação de técnicas de sensoriamento remoto, focando a classificação temática dos usos da terra, na qual foi utilizada a classificação digital supervisionada pelo método de máxima verossimilhança (Max Ver). A planilha eletrônica foi utilizada, principalmente para analisar os dados, gerando gráficos e tabelas comparativas, a fim de facilitar o processo de avaliação dos resultados.

Os métodos aplicados nesse trabalho tangenciam a análise dos usos da terra no município de Jaguari, com foco na verificação da localização espacial dos usos e de suas características. Especificamente, analisaram-se as incidências de cada uso da terra nos distritos municipais e nos distintos fatiamentos altimétricos e clinográficos segmentados para a área de estudo.

A primeira análise realizada refere-se a classificação do uso da terra, na qual, segmentou-se a imagem nos seguintes usos: água, áreas úmidas (lavouras de arroz), vegetação, lavouras, solo exposto e campo. Para cada uso do solo, aplicou-se uma determinada composição na imagem a fim de realçar determinado uso da terra e realizar a coleta das amostras. Exemplificando tal procedimento, a Figura 2, contextualiza todas as composições entre as bandas. Ainda, salienta-se que, coletaram-se
997 amostras, sendo 168 de água, 189 de áreas úmidas (lavouras de arroz), 303 de vegetação, 251 de lavouras, 49 de solo exposto e 37 de campo.

Na realização da classificação digital dos dados, a imagem recebeu um tratamento espacial, a fim de realizar a conversão das informações originais (disponíveis em níveis digitais) para refletância (dados físicos), conforme metodologia evidenciada no sítio do USGS (2015). Essa etapa é de extrema importância para a realização de uma classificação digital, uma vez que possibilita excluir as interferências das camadas atmosféricas na análise final dos dados, gerando um resultado fisicamente correto.

Com isso, fez-se uso da equação disponibilizada no sítio do USGS para realizar a conversão dos níveis digitais da imagem para refletância (Equação 1). Ainda, deve-se destacar que todas as bandas utilizadas foram pós-processadas. Além disso, há na Tabela 1 a explicação para cada um dos elementos da equação (variáveis e constantes).

$$
\rho \lambda=M_{\rho} * Q_{\text {cal }}+A_{\rho}
$$

Tabela 1. Variáveis e constantes dispostas na Equação 1 (os valores para Mo e Qcal foram obtidos a partir do arquivo MTL das imagens obtidas do sítio do USGS)

\begin{tabular}{|c|c|}
\hline $\begin{array}{l}\text { Elementos da } \\
\text { fórmula }\end{array}$ & Significado \\
\hline$\rho \lambda$ & $\begin{array}{l}\text { Radiância Espectral do sensor de } \\
\left.\text { abertura (unidade: Watts } /\left(m^{2} s r \mu m\right)\right) \text {. }\end{array}$ \\
\hline$M_{\rho}$ & $\begin{array}{l}\text { Fator multiplicativo de redimen- } \\
\text { sionamento da banda (Banda 1: } \\
\text { 0,01290900; Banda 2: 0,01321900; Ban- } \\
\text { da 3: 0,01218100; Banda 4: 0,01027100; } \\
\text { Banda 5: 0,00628560; Banda 6: } \\
\text { 0,00156320; Banda 7: 0,00052688; Ban- } \\
\text { da 8: 0,01162400; Banda 9: 0,00245660; } \\
\text { Banda 10: 0,00033420). }\end{array}$ \\
\hline$Q_{c a l}$ & $\begin{array}{l}\text { Fator de redimensionamento aditivo } \\
\text { específico (Banda 1:-64,542720; Banda } \\
\text { 2: -66,092540; Banda 3: -60,903710; } \\
\text { Banda 4: -51,357440; Banda 5: } \\
\text {-31,428190; Banda 6: -7,815910; Banda } \\
\text { 7:-2,634380; Banda 8: -58,122490; Ban- } \\
\text { da 9: -12,282850; Banda 10:0,100000). }\end{array}$ \\
\hline$A_{\rho}$ & $\begin{array}{l}\text { Os valores de nível digital da banda, } \\
\text { ou seja, é a entrada da própria banda } \\
\text { no cálculo. }\end{array}$ \\
\hline
\end{tabular}

Fonte: Elaborado pelos autores 
Após a etapa de coleta de amostras, pode-se, então prosseguir para a aplicação do algoritmo Max Ver e, a partir disso, obter a classificação da área de estudo. Assim, analisaram-se: a classificação de modo geral para a área de estudo, a classificação em relação a área de cada distrito de Jaguari (4 distritos), a quantificação das feições do uso da terra em relação aos intervalos altimétricos, e essa mesma segmentação, porém com a apreciação dos dados a partir dos distintos fragmentos clinográficos.

Ainda, deve-se fazer referência ao mapeamento altimétrico e o clinográfico, conforme contextualizado a seguir. Ambos os mapeamentos foram obtidos junto a imagem do SRTM por meio do aplicativo ARCGIS ${ }^{\circledR}$. Para facilitar o entendimento de construção das referidas bases cartográficas, a seguir explicitar-se-á cada uma delas.

O mapa altimétrico foi obtido a partir da segmentação em classes da imagem SRTM. Para haver essa divisão de valores, utilizou-se o critério estatístico do quartil, obtendo assim, três classes isométricas. Utilizou-se tal critério a fim de repartir a área homogeneamente e deixando-a da forma mais representativa possível.

Tocante ao desenvolvimento dos intervalos clinográficos, pode-se destacar que houve a segmentação da área igualmente ao critério adotado para a altimetria, ou seja, em intervalos homogêneos, com a adoção do

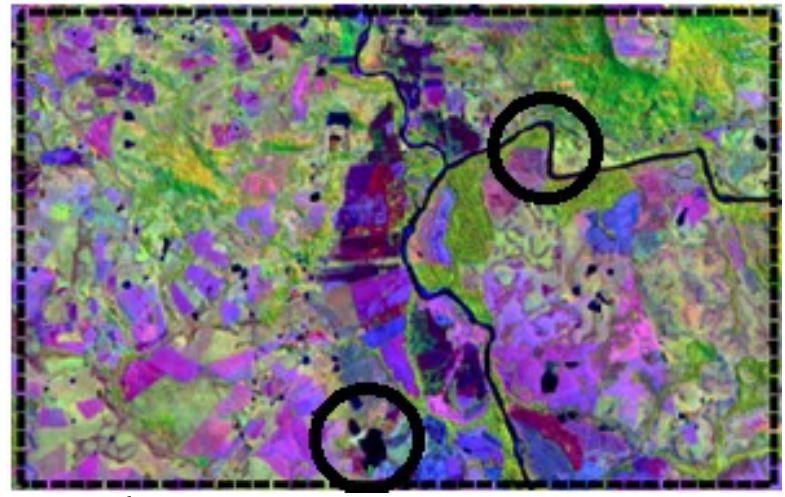

Água assinalada em tons de azul escuro

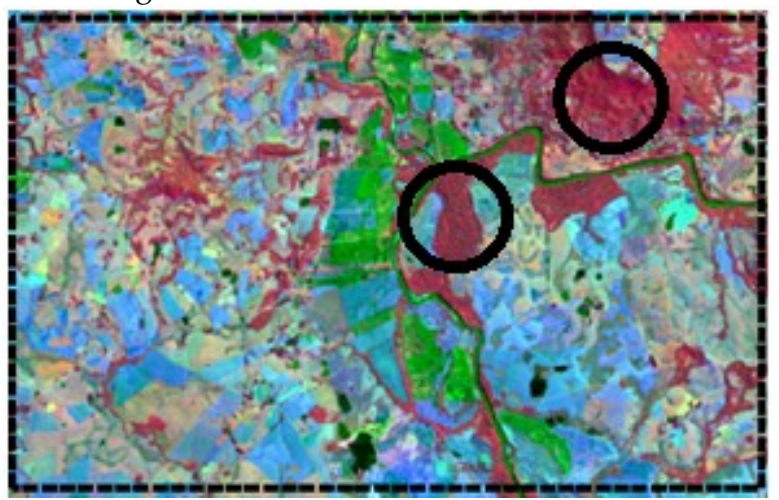

Vegetação assinalada em tons de vermelho

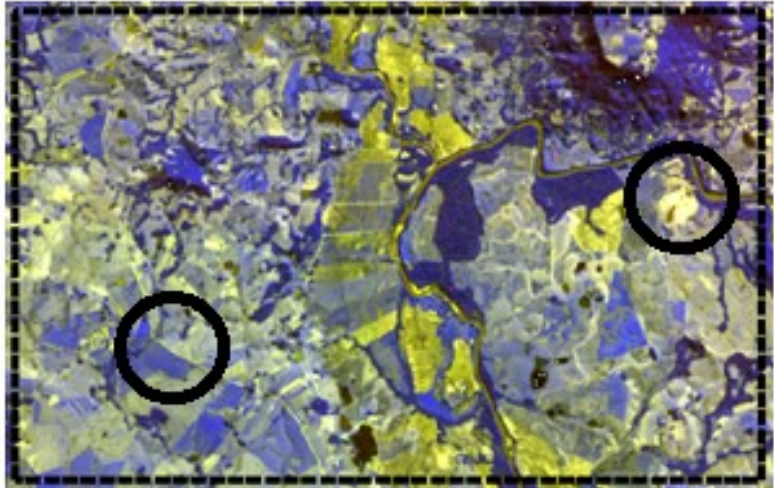

Solo exposto assinalado em tons de branco/bege

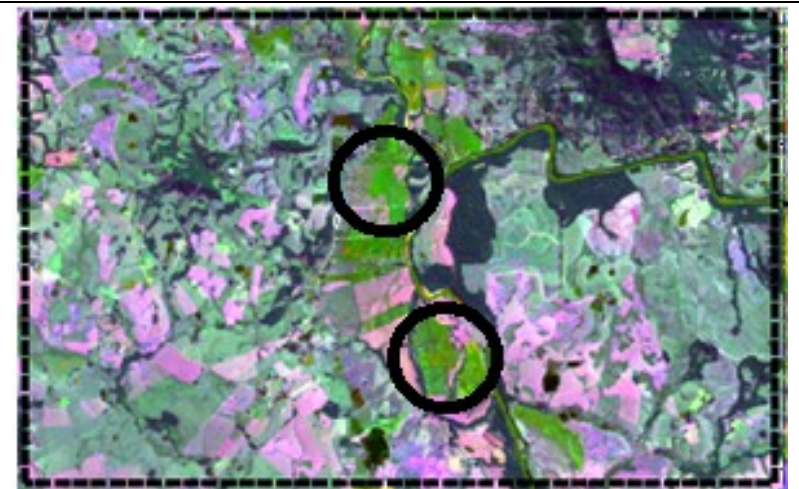

Áreas úmidas assinaladas em tons de verde claro

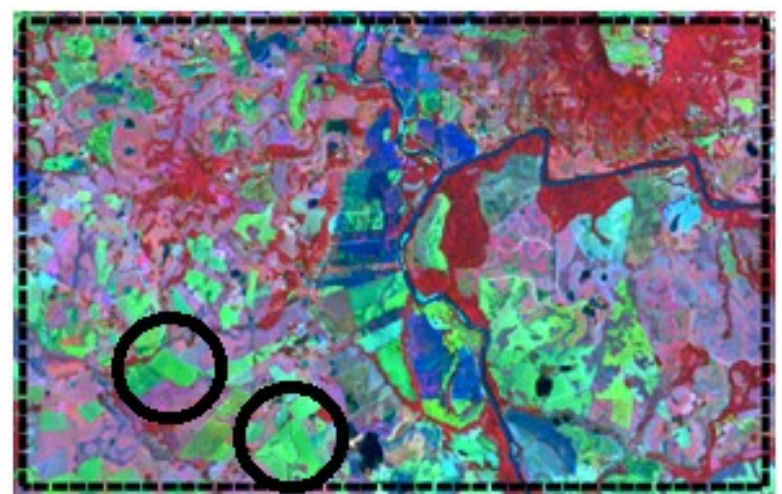

Lavouras assinaladas em tons de verde claro

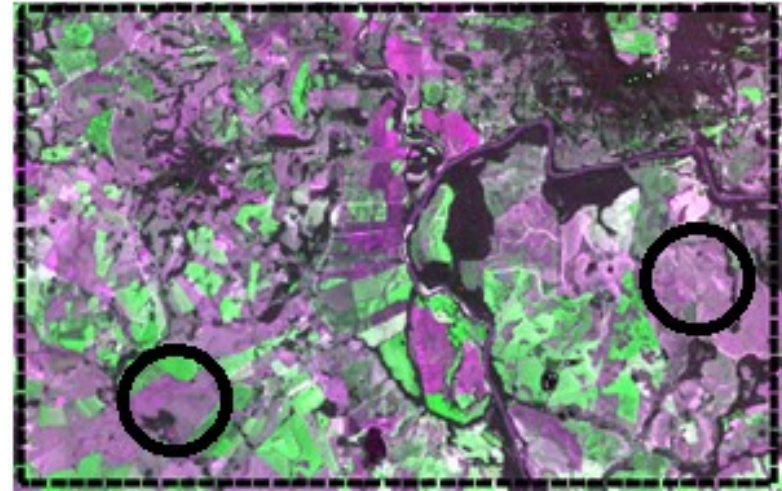

Campo assinalado em tons de rosa

Figura 2 - Composições RGB utilizadas a fim de distinguir os objetos terrestres, e, dessa forma, facilitar a coleta de amostras

Fonte: Elaborado pelos autores 
conceito estatístico do quartil. Porém, salienta que, devido à declividade não apresentar valores inteiros, os mesmos foram "arredondados", a fim de haver uma maior representatividade dos dados finais.

Uma última análise realizada sobre a caracterização dos usos da terra refere-se às áreas de lavouras e as úmidas, as quais representam as áreas agricultáveis do município. Portanto, estimaram-se, com maior certeza, estas áreas, realizando uma "reamostragem" da classificação, ou seja, quantificando apenas as áreas "expressivas", com valores de no mínimo 1 há (áreas contínuas). De tal modo, possíveis equívocos na classificação digital serão excluídos da estimativa final dessas áreas. Assim, implementando o processo metodológico, com a segmentação das lavouras e das áreas úmidas em áreas "expressivas", superiores a 1 ha, as mesmas foram (re) mapeadas e (re) caracterizadas.

\section{Resultados}

A partir da aplicação dos procedimentos metodológicos obteve-se, a caracterização geral do uso da terra no município de Jaguari, com ênfase a espacialização dos usos da terra nos distritos municipais, nos intervalos altimétricos e clinográficos.

Ressalta-se, em primeira instância, o resultado obtido do uso da terra, de forma geral, para toda a área. Assim sendo, o uso da terra com maior incidência no município de Jaguari refere-se ao solo exposto, com 35,3\% (237,8 $\mathrm{km}^{2}$ ) da área, caracterizado em áreas em torno das lavouras, nas estradas sem pavimentação e, ainda, em áreas agricultáveis sem cobertura de gramíneas ou em locais com incidência dispersa de árvores.

O segundo tipo de uso com a maior frequência na área de estudo são as lavouras, com 22,3\% (150,1 km²). Estas são caracterizadas por pequenas áreas homogêneas, isto é, não há grandes extensões contínuas de lavouras, uma vez que o município de Jaguari possui predomínio de minifúndios. Dentre as culturas observadas no município, podem-se destacar as plantações de soja, porém, deve-se fazer referência a inúmeras outras culturas, que são utilizadas dentro das pequenas propriedades rurais, com ênfase ao fumo e ao milho.

Os terceiros usam com maior incidência refere-se às áreas com vegetação (englobadas por matas nativas e áreas de reflorestamentos), com 22,1\% da área (148,5 $\mathrm{km}^{2}$ ). As áreas de vegetação estão presentes, principalmente, nos locais com mudanças altimétricas bruscas, perfazendo, dessa forma, áreas contínuas de grandes extensões, notificando, dessa forma, um alto grau de preservação, principalmente nas encostas dos morros.

Já o quarto uso da terra com maior presença em Jaguari, refere-se aos campos, com $15,7 \%$ da área (105,5 $\mathrm{km}^{2}$ ), referenciando os locais, principalmente, com incidência da pecuária, e localizados nas áreas com as menores cotas altimétricas do relevo.
O restante da área é ocupado por usos da terra com áreas menos expressivas, referindo-se às áreas úmidas $\left(3,0 \%\right.$ da área, mapeando $\left.20,1 \mathrm{~km}^{2}\right)$, às águas $(1,3 \% \mathrm{da}$ área, mapeando $\left.8,8 \mathrm{~km}^{2}\right)$ e à mancha urbana $(0,3 \%$ da área, mapeando $\left.2,2 \mathrm{~km}^{2}\right)$. Deve-se destacar que as áreas úmidas, notoriamente referem-se às áreas próximas aos corpos hídricos, bem como, com maior respaldo as áreas com cultivo orizícola. Já a "água" representa os corpos hídricos presentes no município, tangenciando três diferenciações: o rio Jaguari, o rio Jaguarizinho e os açudes.

Quanto a área urbana, deve-se fazer um respaldo especial, pois a mesma foi obtida por meio da vetorização manual, tendo como base a imagem aérea do aplicativo Google Earth.

O segundo item de análise, refere-se a espacialização do uso da terra junto a cada distrito do município, no qual está dividido em quatro: o $1^{\circ}$ distrito denominado de Sede, o $2^{\circ}$ distrito denominado Santo Izidro, o $3^{\circ}$ distrito denominado Ijucapirama e o $4 \stackrel{0}{\circ}$ distrito denominado Taquarichim. Assim sendo, após obter a classificação e convertê-la para um arquivo no formato vetorial (shapefile - polígonos), os mesmos foram correlacionados com a área abrangente de cada um dos distritos e, dessa forma, analisaram-se as características particulares de cada lugar.

Com isso, obteve-se, o mapa geral dos distritos, presente na Figura 3, e o gráfico de quantificação dos usos da terra, nas Figuras 4 e 5. Ainda, criaram-se dois gráficos com duas características particulares: a primeira referente a porcentagem do uso da terra em relação a área de cada um dos distritos, verificando, dessa forma, a importância geral de cada uso da terra na caracterização de cada local; já a segunda análise objetiva-se constatar a porcentagem do uso da terra (geral/total) disposto naquele determinado distrito, objetivando, dessa forma, verificar quais usos possuem maior incidência em uma determinada área.

A partir da análise da Figura 4, verifica-se que, com exceção do distrito de Santo Izidro, os demais apresentam solo exposto como sendo o uso com maior frequência. Em Santo Izidro há como uso mais significativo as áreas de lavouras, com cerca de $30 \%$ da área total desse território, se bem, que o referido local suporta a menor quantidade de lavouras em relação ao total das lavouras do município. Porém, Santo Izidro é o distrito que possui a menor área em relação aos demais, com cerca de 90 $\mathrm{km}^{2}$, correspondendo a $14 \%$ da área total (Taquarichim, Ijucapirama e a Sede abrangem, respectivamente, 21\%, $31 \%$ e $34 \%$ em relação a área total do município).

Analisando, especificamente o distrito de Santo Izidro, constata-se, conforme já exposto, a maior presença de lavouras (com cerca de 30\%). Contudo, na análise geral dos usos, esse local contabiliza mais de $40 \%$ das áreas úmidas do município, que expressam áreas com plantio orizícola. Assim sendo, verifica-se o quão importante o referido distrito é para o município e, apesar do mesmo ser o menor de todos é aquele que contabiliza áreas 


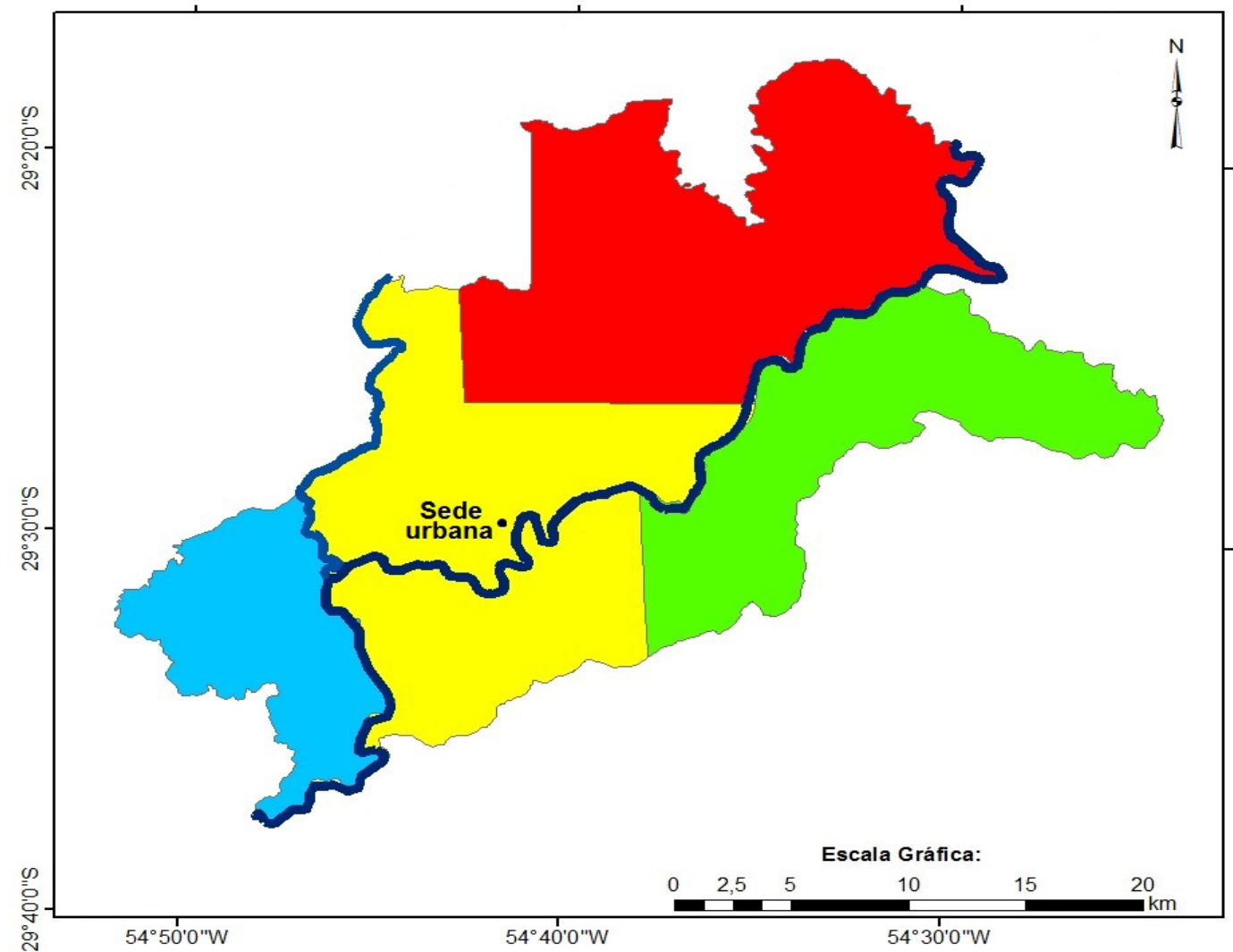

Distritos do municipio de Jaguari/RS

Informações cartográficas:

Sistema de Referência SIRGAS 2000

Sistema de Coordenadas UTM Fuso $21 \mathrm{~J} \mathrm{Sul}$

Convençöes: Distritos: Taquarichim Sede Santo Izidro ljucapirama Corpos Hidricos: Rio Jaguari

Rio Jaguarizinho

Figura 3 - Distritos de Jaguari

Fonte: Elaborado pelos autores

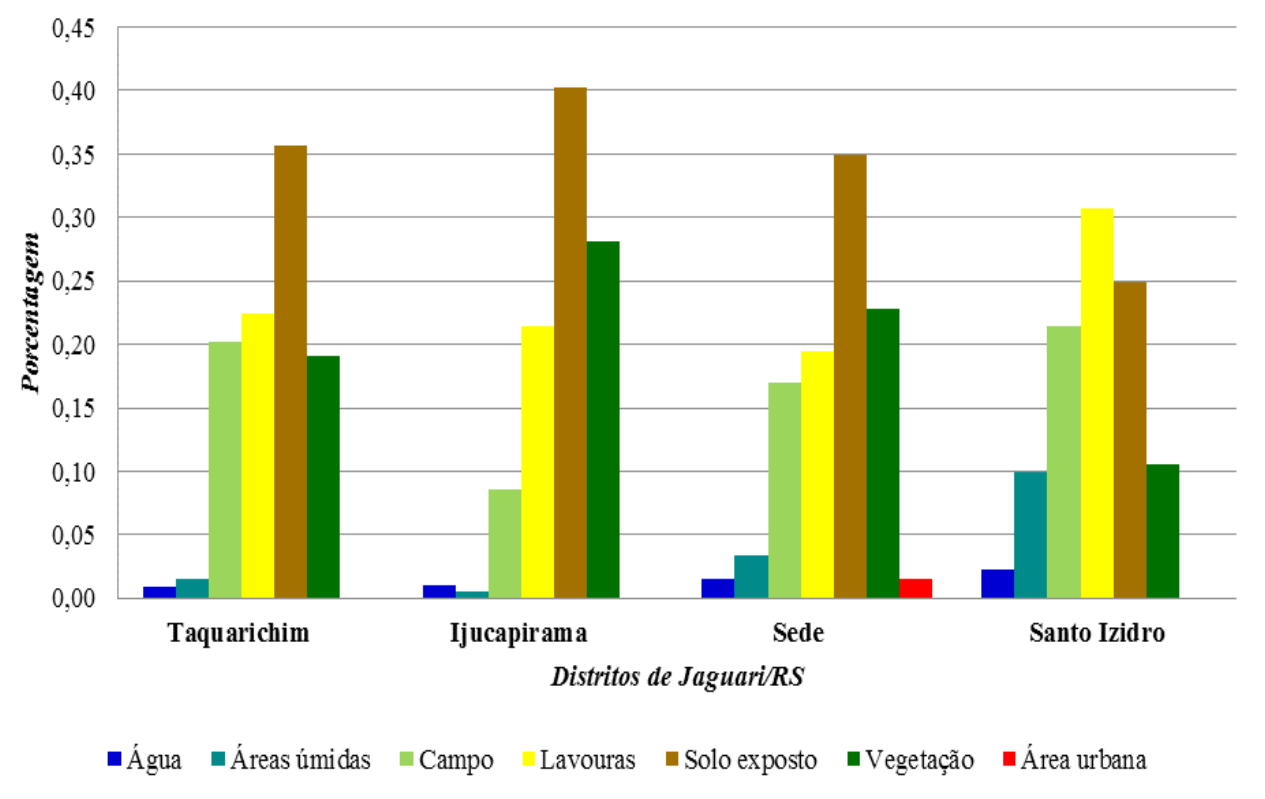

Figura 4 - Porcentagem do uso da terra presente na área geral de cada distrito de Jaguari Fonte: Elaborado pelos autores 


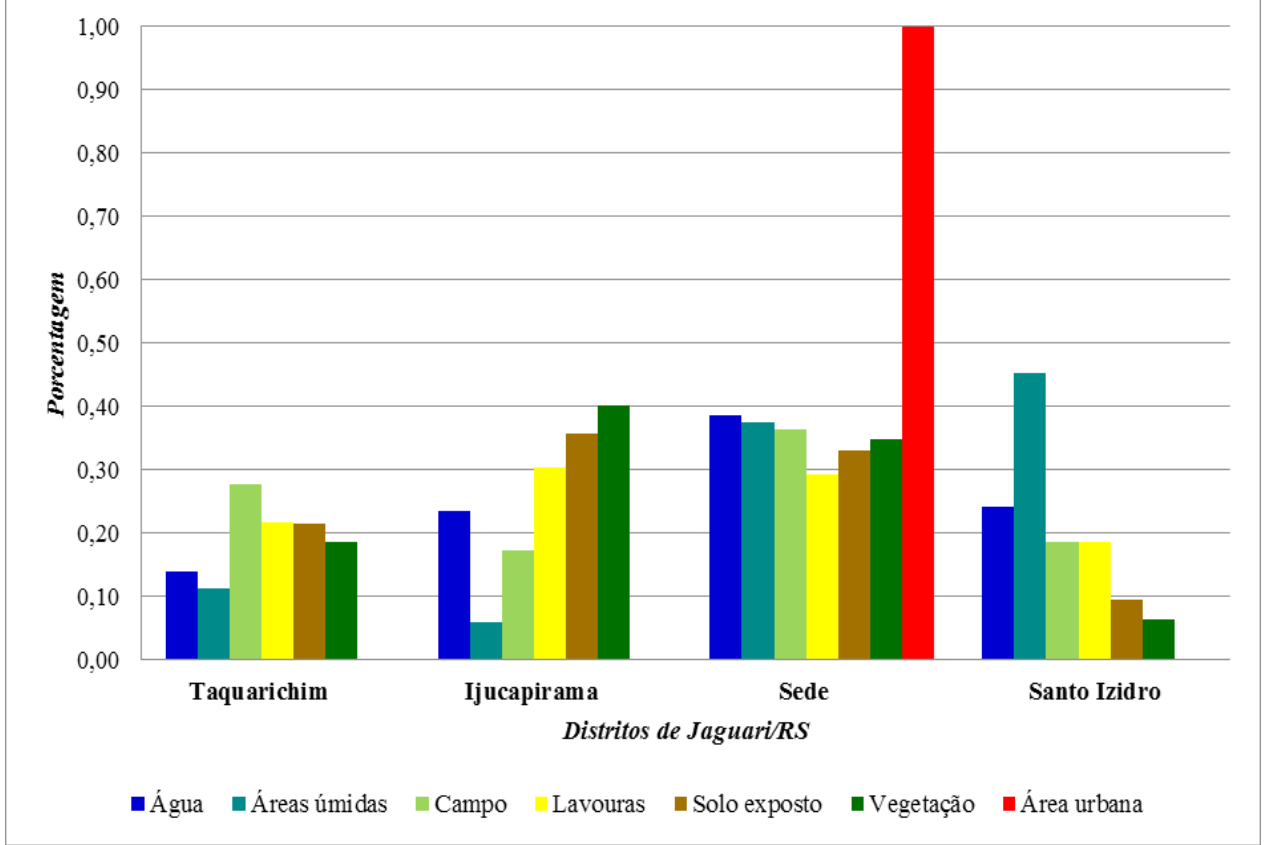

Figura 5 - Porcentagem do uso da terra total localizado em cada distrito de Jaguari Fonte: Elaborado pelos autores

significativas de plantios (lavouras em geral e de arroz). Ainda, constata-se que mais de $20 \%$ da área do distrito possui ocupação de campos, logo, para o uso da pecuária.

Nesse sentido, verifica-se que cerca de $60 \%$ da área do distrito é aproveitada para a agricultura e pecuária (30\% de lavouras, $10 \%$ de áreas úmidas e $20 \%$ de campos). Ainda, referente às áreas com incidência de solo exposto, pode-se destacar que parte desses locais classificados podem englobar áreas de uso orizícola (em outras partes do ano), uma vez que é adotado, como padrão, o rodízio de áreas para o plantio da referida cultura. Em contrapartida, o referenciado distrito possui a menor incidência de áreas verdes (em relação aos demais), com cerca de $10 \%$ de sua área total.

Outra análise que sobressaiu em relação às demais se refere às áreas com incidência de vegetação. Analisou-se que os distritos que possuem as maiores áreas de preservação (com remanescentes de vegetação) são Ijucapirama e a Sede, com cerca de $28 \%$ e $23 \%$ da sua própria área e com cerca de $40 \%$ e $35 \%$ do total de vegetação do município, respectivamente.

O terceiro procedimento realizado na etapa metodológica consistiu na análise dos usos da terra presentes nos intervalos altimétricos. Assim sendo, a segmentação das classes resultou em valores praticamente homogêneos, com mínimas discrepâncias, com uma porcentagem de 33,02\% (áreas altas), 33,44\% (áreas intermediárias) e 33,54\% (áreas baixas). A partir dessa segmentação, a área de estudo ficou caracterizada com a representação das partes mais baixas (topograficamente) ao sul e as mais altas ao norte.

Salienta-se, ainda, que as áreas altas comportam o intervalo altimétrico de 244 a $448 \mathrm{~m}$, as áreas intermediárias de 135 a $244 \mathrm{~m}$ e, por fim as áreas baixas de 78 a 135 m. Assim sendo, a partir da Figura 6 há uma síntese dos intervalos altimétricos da área e na Figura 7, a caracterização dos usos da terra em cada intervalo.

Com a análise da Figura 7, verifica-se que as áreas altas possuem como incidência de usos da terra mais frequente as áreas com vegetação (49\% do total de vegetação), solo exposto ( $36 \%$ do total de solo exposto) e lavouras (27\% do total de lavouras). Assim, verifica-se que quase $50 \%$ das áreas com adensamento de vegetação estão localizadas nas áreas mais altas do município.

As áreas intermediárias possuem a incidência de quatro usos do solo com uma maior porcentagem em relação aos seus totais: solo exposto (37\%), vegetação $(36 \%)$, campo (34\%) e lavouras (30\%). Por fim, as áreas mais baixas possuem, logicamente, as maiores porcentagens de áreas úmidas (87\%) e de água (67\%). Se bem que nesse local há uma parcela significativa de campos (47\%) e de lavouras (43\%).

Por fim, a última análise a ser realizada, refere-se a quantificação do uso da terra em relação aos distintos perfis clinográficos (Figura 8 e 9). Deve-se ressaltar que, devido os valores da declividade terem passado 


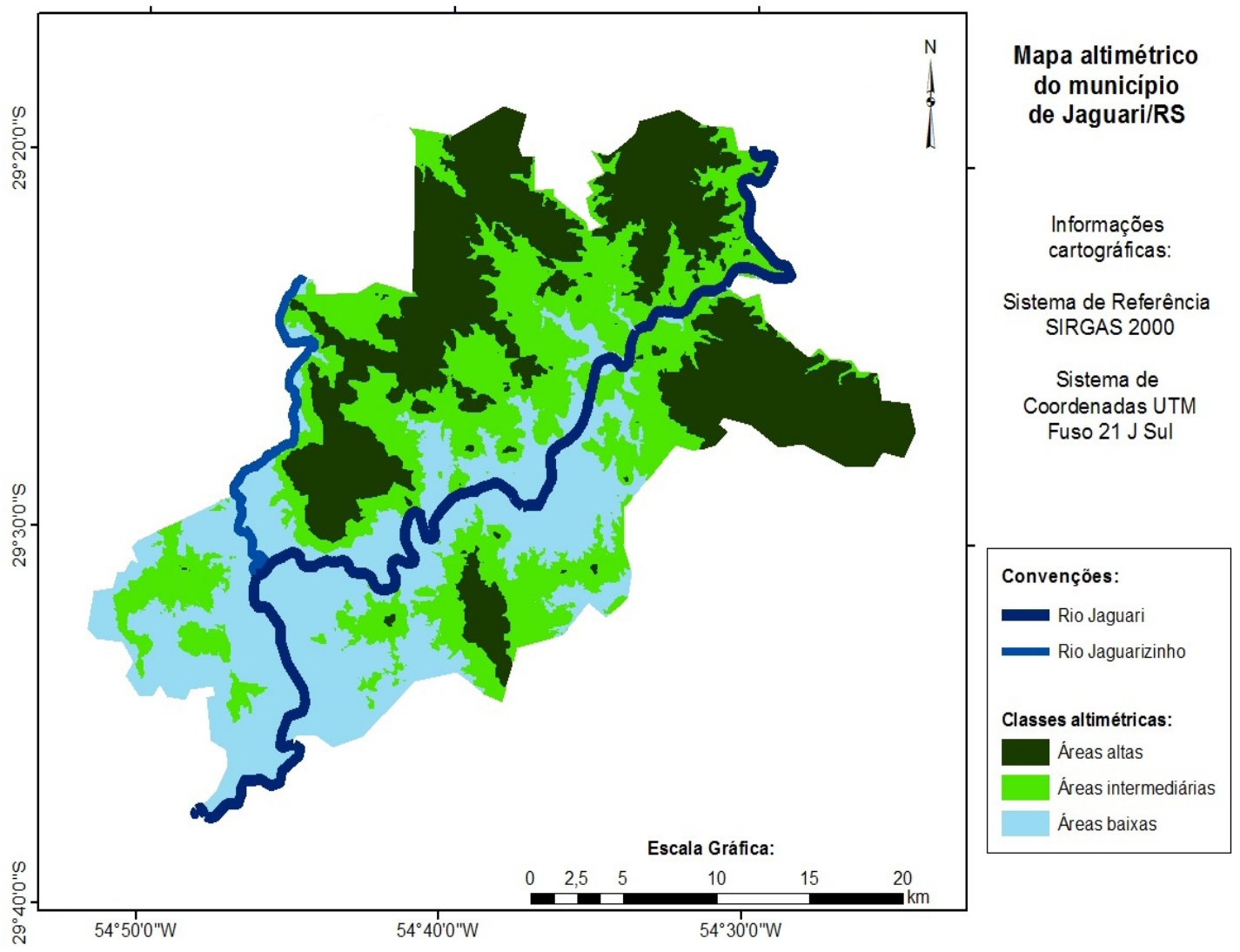

Figura 6 - Intervalos altimétricos segmentados pelo critério do quartil.

Fonte: Elaborado pelos autores

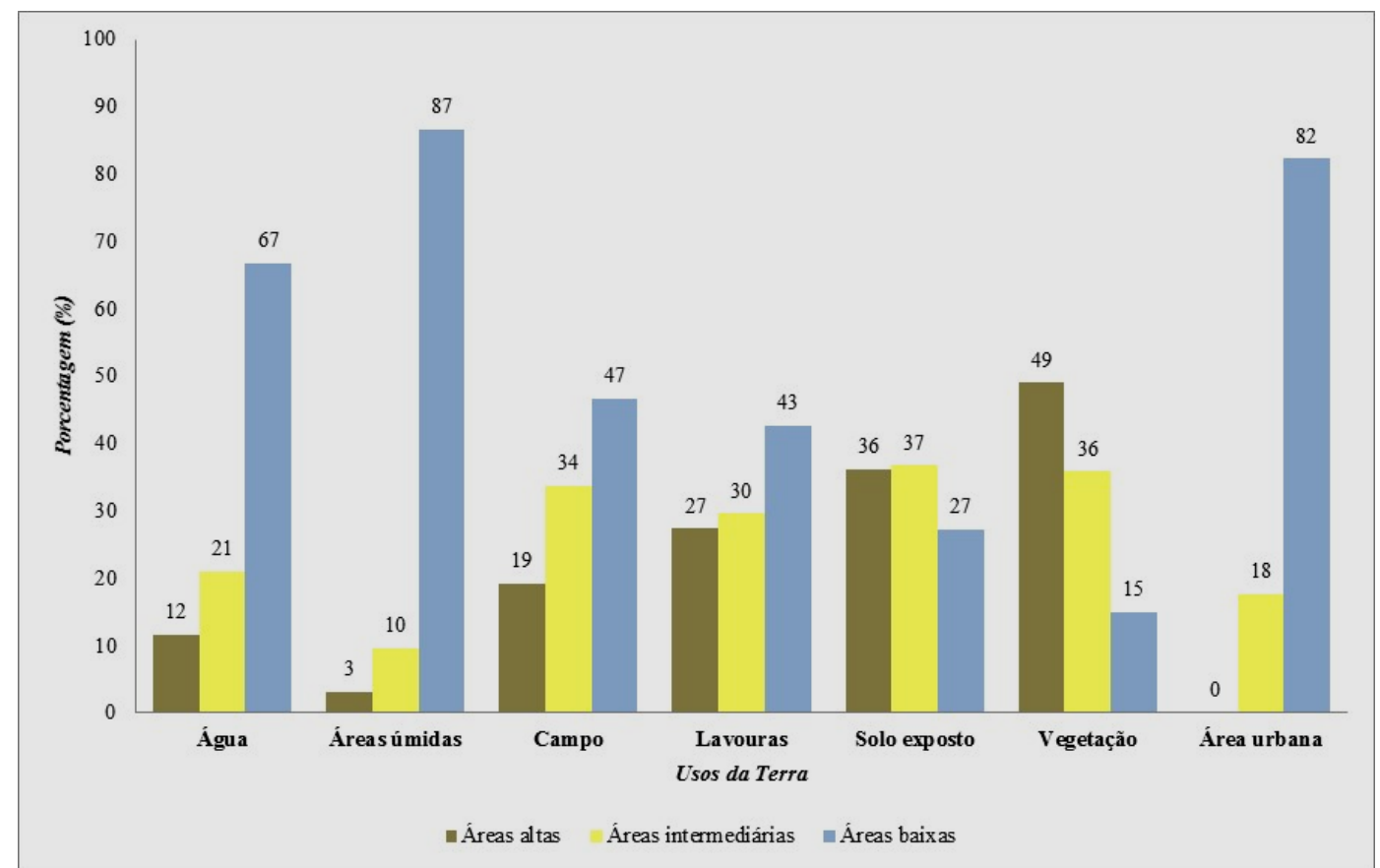

Figura 7 -Gráfico das áreas para cada uso da terra: relação da porcentagem de cada uso em cada intervalo altimétrico

Fonte: Elaborado pelos autores 


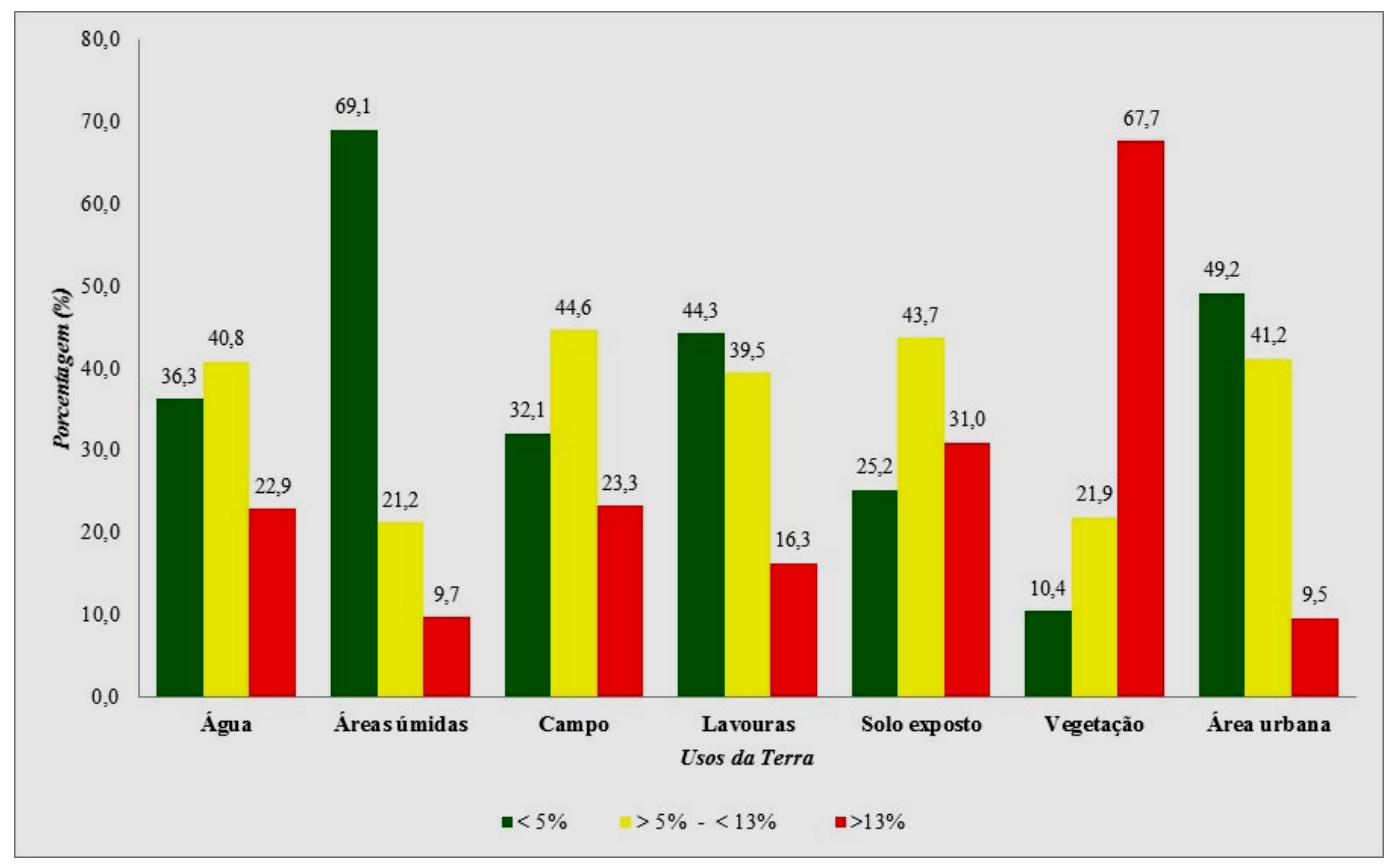

Figura 8 - Uso da terra em função dos três intervalos clinográficos: relação da porcentagem de cada uso da terra. Fonte: Elaborado pelos autores

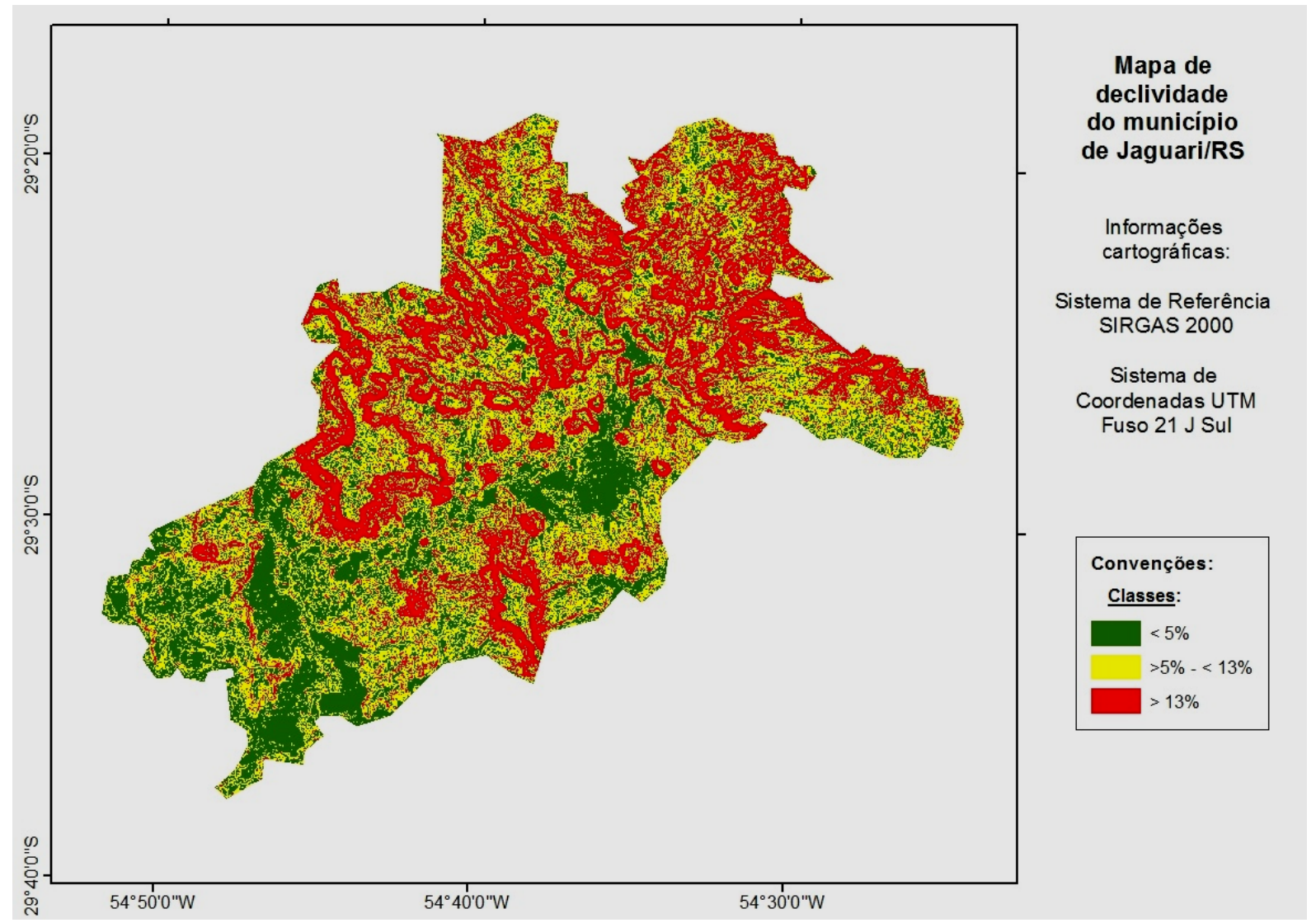

Figura 9 - Mapa clinográfico segmentado em três intervalos.

Fonte: Elaborado pelos autores 
pelo arredondamento dos dados, acabou havendo um menor grau de homogeneidade entre as classes. Assim, obtiveram-se valores de $29 \%$ da área para o intervalo de declividade inferior a " $5 \%$ ", $37 \%$ da área para as declividades entre " 5 a $13 \%$ " e $34 \%$ da área para o intervalo superior a " $13 \%$ ".

Com a análise das figuras anteriores denota-se que no intervalo clinográfico que caracteriza as áreas planas $(<5 \%)$ obteve, com porcentagens mais significativas: as áreas úmidas, a área urbana e as lavouras, denotados com $69 \%, 49 \%$ e $44 \%$ de frequência de cada uso, respectivamente. Esse resultado vai ao encontro da ideologia organizacional de construir cidades e lavouras nas áreas mais planas, visto que essas áreas tentem a facilitar a organização e viabilizar a utilização de máquinas agrícolas. No intervalo clinográfico intermediário há destaque para os campos (com $45 \%$ ), solo exposto (44\%) e água e área urbana (ambas com 41\%). Nas maiores declividades há um predomínio das áreas com vegetação (com $68 \%$ ). Ressalta-se, que as porcentagens analisadas tangenciam a quantificação para com o uso do solo, ou seja, a porcentagem é referente ao total daquele uso do solo analisado, e não da área geral.

Por fim, analisaram-se as áreas exclusivas de lavouras, pois, é a partir dessas áreas que o município de Jaguari gera suas receitas, uma vez que o setor agropecuário abrange cerca de $30 \%$ do Produto Interno Bruto (PIB) do município (IBGE, 2015).

A seguir, contextualizar-se-ão os resultados inerentes do (re) mapeamento das áreas de lavouras, conforme metodologia já identificada. Assim, no que tange a área total de lavouras do município, as mesmas abrangeram um montante de 132,54 km², com 1.292 polígonos espacializados. Já nas áreas úmidas, com a cultura do arroz, houve um total de $12,59 \mathrm{~km}^{2}$ mapeados, abrangendo 121 talhões. Unindo as lavouras às áreas úmidas (arroz) há uma estimativa de aproximadamente $145 \mathrm{~km}^{2}$ de áreas agricultáveis no município, o qual corresponde a $22 \%$ da área de Jaguari.

\section{Conclusões}

Com base nos resultados obtidos, compreende-se que o presente trabalho mostrou-se uma ferramenta importante na análise das condições ambientais, uma vez que possibilitou identificar e quantificar quais são os tipos de uso da terra na área de estudo. Através desses pode-se perceber que os usos de maior incidência são as áreas de solo exposto $(35,3 \%)$ e as áreas de lavoura $(22,3 \%)$, totalizando um percentual de $57,6 \%$ da área do município de Jaguari.

O mapeamento temático dos usos da terra é de grande importância, principalmente quando aliados aos SIGs. Assim, acredita-se que esses estudos tornam-se uma importante ferramenta de auxílio à tomada de decisões, pois os mesmos dispõem elementos de extrema importância para o planejamento ambiental do município, bem como no aporte de dados para a gestão do território. Nesse sentido, com o presente trabalho, espera-se ter conseguido contribuir tanto na construção do conhecimento geográfico desse território, bem como no auxílio a outras discussões e pesquisas futuras tangentes à área estudada.

A realização da classificação digital por meio de duas imagens de datas distintas foi de grande importância a fim de caracterizar, principalmente, as áreas úmidas, com incidência de lavouras orizícolas, bem como das áreas de lavouras. Além disso, o processo foi de grande importância a fim de estimar o total de área plantada no município.

Por fim, ressalta-se a grande importância de analisar a correlação dos usos da terra com classes altimétricas e clinográficas, pois, dessa forma, podem-se estimar características particulares existentes dentro da área de estudo. Ainda, por meio da análise particular da incidência dos usos da terra nos distritos de Jaguari, pode-se verificar as características dos mesmos, e, assim, atribuir as propriedades terrestres de cada território distrital.

\section{Agradecimentos}

Agradecemos à Coordenação de Aperfeiçoamento de Pessoal de Nível Superior (CAPES) pela concessão de bolsas de estudos a segunda autora.

\section{Referências}

AMARAL, A. B.; RIOS, A. de S. GEOPROCESSAMENTO: Mapeamento do uso e ocupação do solo no alto curso do Rio Piedade. Revista de Geografia - PPGEO - v. 2, no 1 (2012). Disponível em: <http://www.ufjf.br/ revistageografia/files/2012/10/GEOPROCESSAMENTOMAPEAMENTO-DO-USO-E-OCUPA $\%$ C $3 \% 87 \%$ C $3 \% 83 \mathrm{O}-$ DO-SOLO-NO-ALTO-CURSO-DO-RIO-PIEDADE.pdf>. Acesso em 30 mai.2015.

COLLISCHONN, B.; COLLISCHONN, W. Classificação multitemporal de uso do solo usando imagens CBERS para fins de simulação e gerenciamento de recursos hídricos na bacia do rio Quaraí. Anais XIV Simpósio Brasileiro de Sensoriamento Remoto, Natal, Brasil, 25-30 abril 2009, INPE, p. 4687-4692.

IBGE - Instituto Brasileiro de Geografia e Estatística. IBGE Cidades - Rio Grande do Sul, Jaguari. Disponível em: <http://www.cidades.ibge.gov.br/xtras/temas. php? lang $=\& \operatorname{codmun}=431110 \&$ idtema $=16 \&$ search $=$ rio-grandedo-sul |jaguari I sintese-das-informacoes $>$. Acesso em 16 fev.2015. 
MICROSOFT. Microsoft ${ }^{\circledR}$ Office Excel, 2007.

USGS (U.S. Geological Survey). EarthExplorer. Disponível em: <http://earthexplorer.usgs.gov/>. Acesso em: 19 fev. 2015.

WEISS, C. V. da C.; LIMA, L. T. de; TERCEIRO A. M.; GAUER, N. P. Mapeamento do uso e ocupação do solo utilizando imagens de satélite do sensor TM/Landsat 5 no litoral sul do Rio Grande do Sul, Brasil. Anais XVI Simpósio Brasileiro de Sensoriamento Remoto - SBSR, Foz do Iguaçu, PR, Brasil, 13 a 18 de abril de 2013, INPE. Disponível em: <http://www.dsr.inpe.br/sbsr2013/files/ p0552.pdf $>$. Acesso em 30 mai.2015. 